\title{
Materiais vegetais aplicados ao manejo agroecológico de Meloidogyne incognita em tomateiro
}

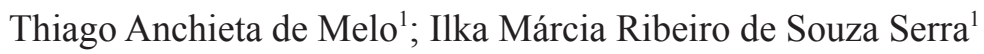

\begin{abstract}
${ }^{1}$ Universidade Estadual do Maranhão, Departamento de Química e Biologia, Laboratório de Fitopatologia, Av. dos Portugueses, 1966 - Vila Bacanga, São Luís - MA, Brasil, CEP 65080-805

Autor para correspondência: Thiago Anchieta de Melo (thiagoanchieta@gmail.com)

Data de chegada: 14/11/2017. Aceito para publicação em: 13/10/2018.
\end{abstract}

$10.1590 / 0100-5405 / 187851$

\section{RESUMO}

Melo, T.A.; Serra, I.M.R.S. Materiais vegetais aplicados ao manejo agroecológico de Meloidogyne incognita em tomateiro. Summa Phytopathologica, v.45, n.1, p.97-103, 2019.

O objetivo deste trabalho foi avaliar o efeito de folhas frescas trituradas de leucena, mandioca e mamona, aplicados como adubação de cobertura, no controle de $M$. incognita em tomateiro e, no desenvolvimento destas plantas em condição de casa-de-vegetação. Os materiais foram aplicados na superfície do solo 30 dias após a germinação das sementes e, após 10 dias, o substrato de cultivo das plantas foi infestado. Plantas cultivadas em solo não infestado serviram para a avaliação do efeito dos materiais sobre o desenvolvimento dos tomateiros. Em ambos os ensaios, foram aplicadas $0,10,20,30$ e $40 \mathrm{~g}$ de folhas frescas trituradas de leucena, mamona e mandioca por $\mathrm{Kg}$ de solo, em tratamentos independentes. A avaliação ocorreu 45 dias após a aplicação dos materiais vegetais. Nos tratamentos onde o solo foi infestado os materiais vegetais incrementaram a massa fresca da raiz e da parte aérea dos tomateiros e inibiram a reprodução do patógeno. Houve diminuição do número de ovos, redução do fator de reprodução, índice de galhas e índice de massas de ovos de $M$. incognita nas plantas dos tratamentos que apresentaram material vegetal, independente da concentração utilizada. Os materiais incrementaram o desenvolvimento das plantas, sendo esse incremento mais pronunciado, quando estas foram cultivadas na presença da leucena, em todas as concentrações do vegetal utilizadas. Tais resultados apontam para o potencial desses materiais vegetais, no controle sustentável do nematoide das galhas em tomateiro.

Palavras-chave: Palavras-chave: agricultura orgânica, adubação verde, nematoide-das-galhas.

\section{ABSTRACT}

Melo, T.A.; Serra, I.M.R.S. Plant materials applied to the agroecological management of Meloidogyne incognita in tomato plants. Summa Phytopathologica, v.45, n.1, p.97-103, 2019.

The objective of this study was to evaluate the effect of fresh leaves of leucaena, cassava and castor bean, applied as cover fertilizers, on the control of M. incognita in tomato plants and on the development of these plants under greenhouse conditions. The materials were applied to the soil surface at 30 days after seed germination and, after 10 days, the plant growth substrate was infested. Plants grown on non-infested soil were used to evaluate the effect of the materials on the development of tomato plants. In both tests, $0,10,20,30$ and $40 \mathrm{~g}$ fresh leaves of leucaena, cassava and castor bean were applied per $\mathrm{kg}$ of soil as independent treatments. The evaluation occurred at 45 days after the application of plant materials. In treatments where the soil was infested, the plant materials increased root and shoot fresh mass of the tomato plants and inhibited the reproduction of the pathogen. There was a reduction in the number of eggs, a reduction in the reproduction factor, gall index and egg mass index of $M$. incognita in the plants of treatments that had plant material, regardless of the used concentration. The materials increased the development of plants and this increase was more pronounced when they were cultivated in the presence of leucaena, at all concentrations of the plant material. These results indicate the potential of such plant materials on the sustainable control of root-knot nematode in tomato plants.

Keywords: organic agriculture, green manuring, root-knot-nematode.

A produção agroecológica de hortaliças tem crescido nos últimos anos, em todo o mundo, principalmente, pela necessidade da proteção da saúde dos produtores, consumidores e também, manutenção da viabilidade produtiva do ambiente. Os sistemas agroecológicos de produção, baseiam-se em uma produção agrícola sustentada na agricultura orgânica. Esta última, por sua vez, é praticada, principalmente, por produtores familiares, uma vez que, nas pequenas propriedades é mais fácil a adequação desse tipo de sistema de produção (25).

A grande vantagem dos sistemas agroecológicos de produção está na não utilização de agrotóxicos no ambiente. O Brasil, no ano de 2000, ocupava a décima quinta posição em área de produção, com aproximadamente $100 \mathrm{mil}$ hectares. Segundo relatório apresentado por Willer \& Yussef (28), em 2004 o país ascende para a quinta posição em virtude da agregação das áreas de pastagens orgânicas. O número de hectares de produção orgânica no Brasil, que correspondia a $0,63 \%$ dos 15,81 milhões de hectares da área mundial em 2000, aumentou para cerca de 3,03\% dos 26,46 milhões de hectares identificados em 2004. Segundo Lhedó (15), em publicação da Secretaria Especial de Agricultura Familiar e do Desenvolvimento Agrário, o Brasil conta hoje com mais de 15.700 unidades de produção orgânica, mais que o dobro registrado no ano de 2013 (6.700 propriedades), sustentada, principalmente, pela agricultura familiar. Dessas, 250 estão sediadas no estado 
do Maranhão (22).

O desenvolvimento de sistemas agroecológicos de produção, alternativos à utilização intensiva de pesticidas, insumos inorgânicos e práticas com baixa sustentabilidade, passam por dificuldades de manejo como qualquer sistema produtivo, especialmente, no que diz respeito ao controle de doenças (15). Nematoides do gênero Meloidogyne Goeldi são os agentes de formação de galhas nas raízes de inúmeras culturas. As galhas nas raízes das plantas se configuram como uma das doenças de planta de manejo mais dificultado, especialmente em sistemas agroecológicos de produção, uma vez que, nematoides são veiculados pelo solo e, nesse ambiente, o controle de fitopatógenos é mais difícil (20). Assim, inúmeras alternativas aplicadas ao manejo sustentável desses fitoparasitas, têm sido desenvolvidas e, dentre elas, a adição de matéria orgânica oriunda de resíduos vegetais triturados e que apresentam capacidade nematicida $(10,24,26)$.

Diferentes espécies de plantas têm se mostrado capazes de reduzir ou mesmo eliminar nematoides do solo. Esta capacidade está atrelada à capacidade dessas plantas de produzir substâncias nematicidas, servirem como plantas armadilhas ou hospedeiras desfavoráveis ao ataque desses helmintos (10). Dentre estas, as fabáceas, a exemplo da espécie Leucaenna leucocephala (Lam) De Wit, constituem uma das famílias de plantas mais importantes para essa finalidade (2). Nesse contexto, Cunha et al. (5) demonstrou, in vitro, que o extrato de leucena tem potencial para causar a mortalidade de $93 \%$ dos fitonematoides da espécie Panagrellus redivivus L., expostos a ele.

A mamona (Ricinus comunis L.), planta da família Euphorbiaceae, que apresenta importância pelo óleo produzido em suas sementes, também vem sendo indicada no manejo de fitonematoides. O plantio da espécie, dois meses antes do amendoim, foi suficiente para reduzir a população de $M$. arenaria (Neal) (21), M. incognita (Kofoid \& White), M. javanica (Treub) Chitwood e $M$. paranaenses (Almeida \& Carneiro) (6). Outra Euphorbiaceae que apresenta efeitos significativos no manejo de nematoides é a espécie Manihot esculenta Cranstz, popularmente conhecida como mandioca, macaxeira ou aipim. A mandioca é um dos vegetais mais importantes para o Brasil, sendo plantado em todo o território nacional, especialmente, por pequenos produtores. Trabalhos como o de Nasu et al. (19) apontam para o potencial da planta em reduzir o inóculo de fitonematoides nas áreas que recebem resíduos do vegetal ou subprodutos do seu processamento. Os autores verificaram morte de até $100 \%$ de M. incognita expostos à manipueira em condições in vitro, em diferentes concentrações. Adicionalmente, foi verificado pelos autores que a manipueira melhora o desenvolvimento do tomateiro e diminui o parasitismo do nematoide em condições de casa-de-vegetação.

Um cuidado importante deve ser tomado na escolha da planta antagônica incorporada ao sistema de cultivo, uma vez que estas podem interferir no desenvolvimento da planta principal Tal fato foi observado por Herrera \& Marbán-Mendoza (13), quando o plantio de Mucuna spp. como cultura de cobertura inibiu o desenvolvimento do cafeeiro. Além disso, pode ser hospedeira do patógeno.

Dessa maneira, o objetivo deste trabalho foi avaliar o efeito de resíduos orgânicos de folhas frescas trituradas de leucena, mandioca e mamona, aplicados como adubação de cobertura, no controle de M. incognita em tomateiro e, no desenvolvimento destas plantas em condição de casa-de-vegetação.

\section{MATERIAL E MÉTODOS}

\section{Obtenção das mudas}

Os ensaios foram realizados com tomateiros (Solanum lycopersicum L.), cultivar Santa Cruz, por estes apresentarem alto grau de suscetibilidade à espécie Meloidogyne incognita. Além disso, o cultivar testado apresenta as características agronômicas de qualidade e produtividade buscadas pela tomaticultura, sendo adaptado às mais variadas condições de clima e, por isso, é amplamente cultivado em todas as regiões produtoras do país, incluindo o Maranhão $(18,23)$. As sementes do referido cultivar foram desinfestadas por imersão, durante 1 min, em solução de hipoclorito de sódio a 1,5\% e, em seguida, semeadas em sementeiras de poliestireno expandido de 72 células em substrato comercial orgânico para hortaliças $\left(\right.$ Plantmax $\left.^{\circledR}\right)$.

\section{Obtenção e preparo do inóculo do patógeno}

O nematoide foi obtido de plantas sintomáticas e identificados segundo características da região perineal das fêmeas (16), pertencentes à coleção de fitonematoides do Laboratório de Fitopatologia da Universidade Estadual do Maranhão. Após a identificação, as populações de $M$. incognita foram purificadas em tomateiro da cv. Santa Cruz, com 20 dias de idade, produzidos em vasos contendo solo com esterco de vaca curtido (2:1). Utilizou-se como inóculo, suspensão de ovos contendo $5 \mathrm{mil}$ ovos $/ \mathrm{mL}$. As plantas inoculadas foram mantidas em condições de casa de vegetação pertencente ao Laboratório de Fitopatologia da Universidade Estadual do Maranhão. Os ovos de $M$. incognita, que constituíram o inóculo, foram coletados de acordo com a técnica descrita por Hussey \& Barker (14), 30 dias após inoculação.

\section{Aplicação dos resíduos orgânicos, inoculação e avaliação das plantas}

Cinco dias após a germinação das sementes nas bandejas, as plântulas dos tomateiros foram transferidas para vasos de $2 \mathrm{~L}$ de capacidade contendo $1,5 \mathrm{Kg}$ da mistura 'solo + esterco de vaca curtido', na proporção de 2:1. A adição dos materiais vegetais foi realizada 25 dias após o transplantio. Os vasos receberam diferentes proporções de folhas frescas trituradas em moinho mecânico, depositadas na superfície do substrato, sendo: $0,10,20,30$ e $40 \mathrm{~g}$ de folha fresca de leucena, mamona ou mandioca mansa/Kg de solo. A inoculação do nematoide foi realizada 10 dias após a adição da matéria orgânica. Com o auxílio de uma espátula, foram feitas aberturas ao redor do colo da planta e o inóculo foi vertido em torno do colo da planta, na proporção de 5 mil ovos/planta, em um círculo de aproximadamente $2-3 \mathrm{~cm}$ de profundidade, sendo este, coberto em seguida, com o próprio substrato.

Decorridos 45 dias da infestação do patógeno no solo, as plantas foram retiradas do substrato, as raízes lavadas em água corrente, e determinada a massa fresca $(\mathrm{g})$, da parte aérea e das raízes das plantas, os índices de galhas e massas de ovos, número de ovos por planta e fator de reprodução do nematoide (FR) (FR = população final/população inicial). A técnica empregada foi de Hussey \& Barker (14).

Para estimativa do índice de galha, foi utilizada a escala de notas do "International Meloidogyne Project", citada por Taylor \& Sasser (27). Tabela 1

A determinação do peso fresco da biomassa das raízes e parte aérea foi feita logo após a coleta em balança de precisão.

Efeito dos resíduos vegetais sobre o desenvolvimento dos tomateiros

Para esta análise, as sementes de tomate foram diretamente 
Tabela 1. Escala de notas para o índice de galhas e índice de massa de ovos em plantas parasitadas por Meloidogyne incognita, segundo o "International Meloidogyne Project".

\begin{tabular}{cc}
\hline Nota & No de galhas \\
\hline 0 & 0 \\
1 & 1 ou 2 \\
2 & 3 a 10 \\
3 & 11 a 30 \\
4 & 31 a 100 \\
5 & Mais de 100 \\
\hline
\end{tabular}

Fonte: Adaptada de Taylor e Sasser (27).

semeadas em vasos de $2 \mathrm{~L}$ de capacidade contendo $1,5 \mathrm{~kg}$ da mistura 'solo + esterco de vaca curtido' na proporção de 2:1. Transcorridos 30 dias da germinação das sementes, os vasos receberam diferentes proporções de folhas frescas trituradas, depositadas na superfície do substrato, sendo: 0, 10, 20,30 e $40 \mathrm{~g}$ de folha fresca de leucena, mamona ou mandioca $/ \mathrm{Kg}$ de solo. As avaliações de crescimento das plantas (comprimento médio da parte aérea em centímetros) e massa fresca total da planta foram realizadas 30 dias após a semeadura.

\section{Delineamento experimental e análise estatística}

Os experimentos foram realizados ao mesmo tempo para os três tipos de resíduos incorporados (leucena, mamona e mandioca). $\mathrm{O}$ delineamento experimental adotado foi o inteiramente casualizado sendo cinco tratamentos $(0,10,20,30$ e $40 \mathrm{~g})$ com cinco repetições por tratamento. A parcela experimental foi composta por uma planta/vaso. Os dados coletados foram transformados em médias e estas submetidas à análise de variância, sendo comparadas pelo teste de Tukey a $5 \%$ de probabilidade, no software SigmaPlot. Além disso, foi realizada uma análise de regressão linear nos resultados de massa fresca da parte aérea e da raiz, comprimento médio e massa fresca total das plantas, para verificar a correlação dos tratamentos nos parâmetros avaliados. A correlação dos parâmetros "número de ovos" e "fator de reprodução" com os tratamentos aplicados foi determinada a partir de análise de regressão polinomial.

\section{RESULTADOS E DISCUSSÃO}

A partir da análise dos efeitos dos materiais vegetais testados sobre o desenvolvimento de tomateiros parasitados pelo nematoide $M$. incognita, foi possível observar que quanto maiores foram as quantidades de material vegetal incorporada ao solo, mais pronunciado foi o desenvolvimento das plantas, refletido na massa fresca da parte aérea e da raiz (Figura 1).

$\mathrm{Na}$ avaliação da massa fresca da parte aérea, foi verificado que as plantas do tratamento com leucena, desenvolveram-se melhor que as plantas do tratamento controle (Figura 1A). O mesmo foi observado para o desenvolvimento da raiz dessas plantas (Figura 1D). A análise de regressão linear demonstrou que aumentos progressivos na quantidade de leucena depositados sobre o solo, implicou em aumentos também progressivos do desenvolvimento das plantas.

Comportamento semelhante ao descrito acima também foi observado nas plantas que receberam folhas de mamona, uma vez que, em todos os tratamentos, foi observado um incremento no desenvolvimento das plantas, tanto na massa fresca da parte aérea (Figura 1B), quanto na raiz (Figura $1 \mathrm{E}$ ). Incrementos progressivos foram observados à medida que se aumentou a quantidade de folha fresca de mamona. Somente o tratamento que recebeu $10 \mathrm{~g}$ de folhas frescas de mandioca/Kg de solo, não diferiu estatisticamente do controle, na avaliação da massa fresca da parte aérea dos tomateiros (Figura 1C). Entretanto, todas as plantas cujo solo recebeu mandioca, independente da proporção, apresentaram massa fresca da raiz superior ao controle (Figura 1E). Incrementos progressivos foram observados conforme se aumentou a quantidade de de mandioca sobre o solo, como pode ser observado pelos altos valores de $\mathrm{R}^{2}$ da análise de regressão linear.

Tais resultados evidenciam o efeito desses materiais vegetais sobre o desenvolvimento de plantas, mesmo sob estresses bióticos, como os gerados pelo parasitismo do nematoide $M$. incognita, uma vez que, um dos sintomas reflexos da doença é a redução no desenvolvimento das plantas (20).

O parâmetro "número de ovos" foi fortemente influenciado pela presença dos materiais vegetais depositados sobre o solo no cultivo dos tomateiros (Figuras 2A, 2B e 2C). O que se verificou foi redução significativa da capacidade de reprodução do nematoide, quando comparado ao controle, em todos os tratamentos, independentemente do material vegetal aplicado. Foi constatado ainda, redução progressiva no número de ovos do nematoide, conforme se aumentou a quantidade de material aplicado, sugerindo que quanto maiores forem as proporções de leucena, mamona ou mandioca aplicados em cobertura no solo, maior será o controle do fitonematoide.

A resposta observada para o fator "número de ovos" foi confirmada pela variável "fator de reprodução", uma vez que, no tratamento controle, observou-se incrementos aproximados de até 5 vezes a mais da população inicial de ovos depositada nas raízes das plantas (5 mil ovos/planta) e redução do inóculo inicial nos demais tratamentos, para todos os materiais vegetais aplicados (Figura 2D, E e F). Nesta análise, também foi constatado que incrementos progressivos na quantidade de folha fresca triturada, independente da espécie vegetal, depositadas em cobertura sobre o solo de cultivo do tomate, resultou em reduçãoprogressiva na reprodução do $M$. incognita (Figuras 2D, 2E e $2 \mathrm{~F})$.

Charcar et al. (4), quando estudaram o cultivo e incorporação de leguminosas, gramíneas e outras plantas no controle de M. incognita raça 1 , em cenouras, constataram que o fator de reprodução (FR) do nematoide, parâmetro diretamente ligado e dependente do número de ovos gerados, foi menor que 1,0 após o cultivo e incorporação da biomassa fresca de espécies de leguminosas e gramíneas. Os autores verificaram ainda que a média do FR do patógeno para as gramíneas foi 6,5 vezes maior que o FR médio do nematoide para as leguminosas mostrando o elevado potencial destas últimas no manejo de fitonematoides.

Observou-se redução no índice de galhas (IG) e índice de massa de ovos (IMO) nas raízes das plantas, independentemente do material vegetal utilizado. Tal resultado confirma os resultados observados nos parâmetros "número de ovos" e "fator de reprodução". Além disso, o índice de galhas permite a verificação da redução da severidade da doença nas raízes. Tais resultados estão apresentados na Tabela 2.

Trabalhos realizados por Lupwayi \& Haque (17), demonstraram que leucena é uma excelente fonte de $\mathrm{K}, \mathrm{Ca}, \mathrm{Mg}$ e $\mathrm{S}$, além de $\mathrm{N}$. Sabe-se que a adubação equilibrada das plantas é parte integrante do manejo integrado de doenças, uma vez que esta pode predispor direta ou indiretamente as plantas ao ataque de fitonematoides e outros patógenos. Além disso, os nutrientes de um modo geral, podem 

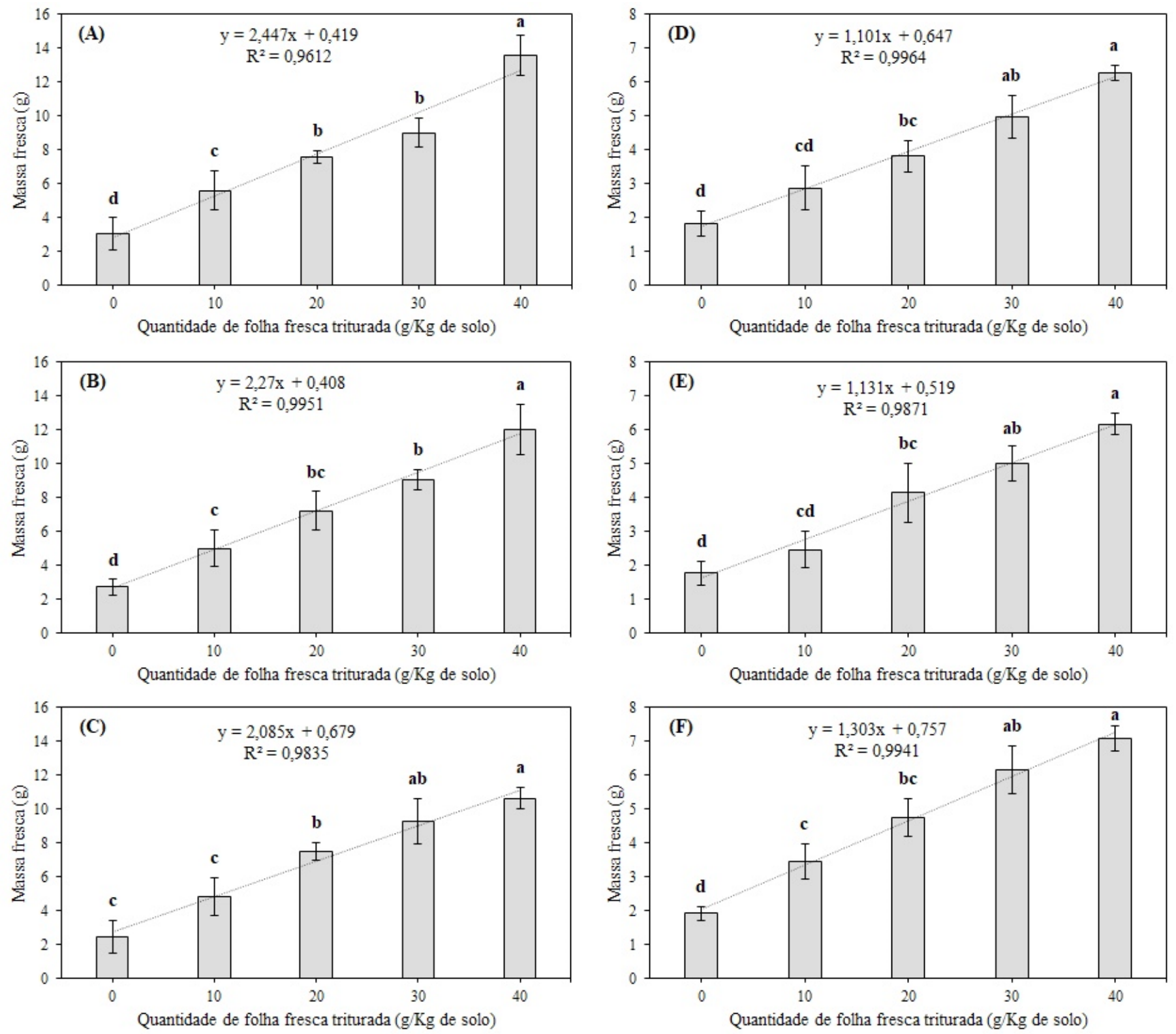

Figura 1. Massa fresca da parte aérea (A, B e C) e da raiz (D, E e F), em gramas ( $\mathrm{g})$, de tomateiros cultivados na presença de resíduos vegetais de folhas de leucena (A e D), mamona (B e E) e mandioca (C e F), e parasitados pelo nematoide Meloidogyne incognita, 45 dias após a inoculação do patógeno. Letras minúsculas, dentro de um mesmo gráfico, não diferem entre si pelo teste de Tukey $(\mathrm{p}=0,05)$. As barras sobre as colunas representam o erro padrão da média.

reduzir ou aumentar a severidade de uma doença, afetar o ambiente, favorecendo ou desfavorecendo os patógenos e também, induzir resistência ou tolerância à planta hospedeira (10). Muitas práticas culturais que reduzem a incidência fitopatógenos estão relacionadas com a sua influência na absorção de nutrientes por parte do vegetal, potencial hospedeiro. A nutrição é sempre mais efetiva nas variedades "tolerantes" às doenças. Plantas com estresse nutricional podem ficar mais predispostas ao ataque de diferentes patógenos. Assim, o elevado potencial nutricional dos resíduos de leucena adicionados ao solo, pode ter contribuído para a baixa incidência do nematoide nas plantas (1). Não se exclui, em absoluto, a possibilidade de um antagonismo direto da leguminosa sobre o M. incognita.

Nesse sentido, Dufour et al. (8) confirmaram que algumas adubações orgânicas podem ser usadas para o controle de nematoides, porque são associadas com redução de infecção e aumento da sobrevivência do número de antagonistas aos nematoides. Geralmente, os resíduos orgânicos mais efetivos para o controle de nematoides são aqueles que possuem alto conteúdo de $\mathrm{N}$, a exemplo da leucena, ou os que contêm compostos nematotóxicos. Uma baixa relação $\mathrm{C} / \mathrm{N}$ tende a aumentar a atividade de microrganismos antagônicos aos nematoides e aumentar a liberação de amônia ao solo (10). Além disso, a decomposição da matéria orgânica aumenta a acumulação de nitritos e nitratos pelo processo de nitrificação (11).

O efeito supressivo da mamona sobre diferentes espécies de nematoides em cana-de-açúcar, incluindo as do gênero Meloidogyne, foi observado por Dinardo-Miranda \& Fracasso (7) que, ao aplicar 1800 

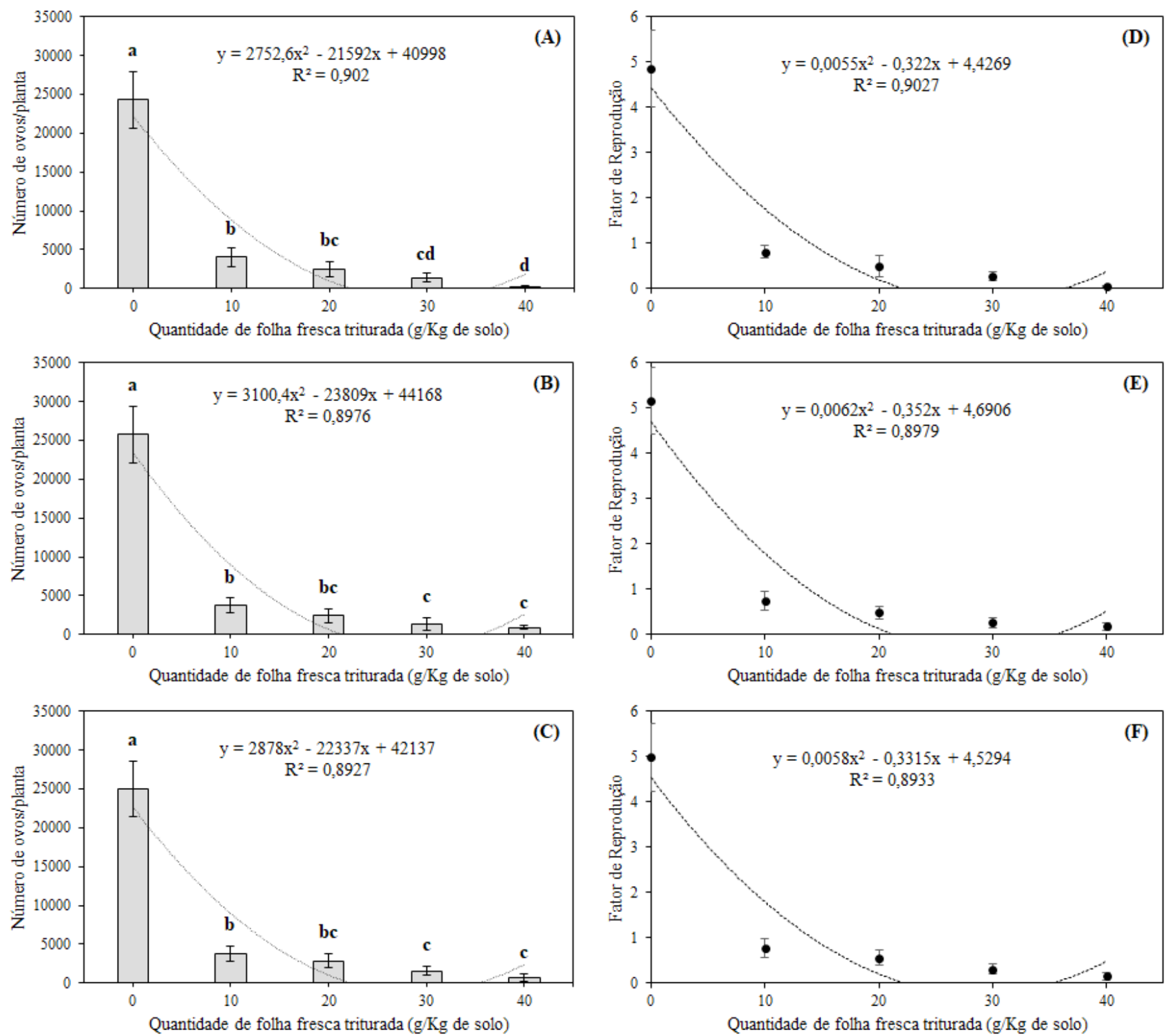

Figura 2. Número de ovos/planta (A, B e C) e fator de reprodução (D, E e F) do nematoide Meloidogyne incognita em tomateiros cultivados na presença de resíduos vegetais de folhas de leucena (A e D), mamona (B e E) e mandioca (C e F), 45 dias após a inoculação do patógeno. Letras minúsculas, dentro de um mesmo gráfico, não diferem entre si pelo teste de Tukey $(\mathrm{p}=0,05)$. As barras sobre as colunas ou sobre os prontos nos gráficos representam o erro padrão da média.

$\mathrm{Kg} /$ ha de torta de mamona, reduziram a reprodução do nematoide em relação à testemunha, além de apresentarem baixos índices de galhas e massa de ovos. O mesmo já havia sido observado por Dutra et al. (9), em ensaio conduzido com cafeeiro infestado por M. exigua Goeldi. Esses autores aplicaram torta de mamona na proporção de $1000 \mathrm{Kg}$ / ha e observaram reduções significativas nas populações do nematoide, tanto nas raízes como no solo das parcelas tratadas, em comparação com as parcelas sem tratamento, provavelmente pela alta concentração de da proteína ricina, uma toxoalbumina com alta capacidade nematicida.

A mandioca vem sendo largamente utilizada no controle de nematoides, principalmente na forma de manipueira com excelentes resultados $(3,12,19)$. A presença do glicosídeo cianogênico linamarina, mesmo que em menores quantidades nas folhas que nas raízes da planta, pela ação da linamarase, libera o gás cianidreto $(\mathrm{HCN})$ altamente tóxico aos animais, portanto, também aos nematoides (10). A eficiência da mandioca em controlar fitonematoses pode estar associada aos produtos gerados pela decomposição da linamarina, presente na planta, que agem de forma antagônica aos fitoparasitas.

As plantas utilizadas como fontes de matéria orgânica e aplicadas como adubos verdes sobre a superfície do solo, não apresentaram efeito inibidor sobre a planta, uma vez que, observou-se aumentos progressivos tanto no comprimento médio das plantas tratadas (Figuras 3A, 3B e 3C), quanto na massa fresca total dessas plantas (Figuras 3D, 3E e 3F). Adicionalmente, efeitos mais pronunciados 
Tabela 2. Índice de galhas (IG) e índice de massa de ovos (IMO) em raízes de tomateiros cultivados em solos cobertos com diferentes quantidades de folhas frescas trituradas de leucena, mamona e mandioca, e parasitados pelo nematoide das galhas, Meloidogyne incognita, 45 dias após a inoculação.

\begin{tabular}{ccccccc}
\hline \multirow{2}{*}{$\begin{array}{c}\text { Quantidade de resíduo } \\
\text { incorporado (g/Kg de solo) }\end{array}$} & \multicolumn{5}{c}{ Fonte de matéria orgânica } \\
\cline { 2 - 7 } & \multicolumn{2}{c}{ Leucena } & \multicolumn{2}{c}{ Mamona } & \multicolumn{2}{c}{ Mandioca } \\
\cline { 2 - 7 } & IG* $^{*}$ & IMO* $^{*}$ & IG $^{*}$ & IMO* $^{*}$ & IG $^{*}$ & IMO* $^{*}$ \\
\hline 0 & 2 & 2 & 2 & 3 & 2 & 3 \\
10 & 2 & 2 & 2 & 2 & 2 & 3 \\
20 & 2 & 1 & 2 & 2 & 2 & 2 \\
30 & 1 & 1 & 1 & 1 & 1 & 1 \\
40 & 5 & 5 & 5 & 5 & 5 & 5 \\
\hline
\end{tabular}

Valores obtidos segundo escala de notas proposta por Taylor e Sasser (27).
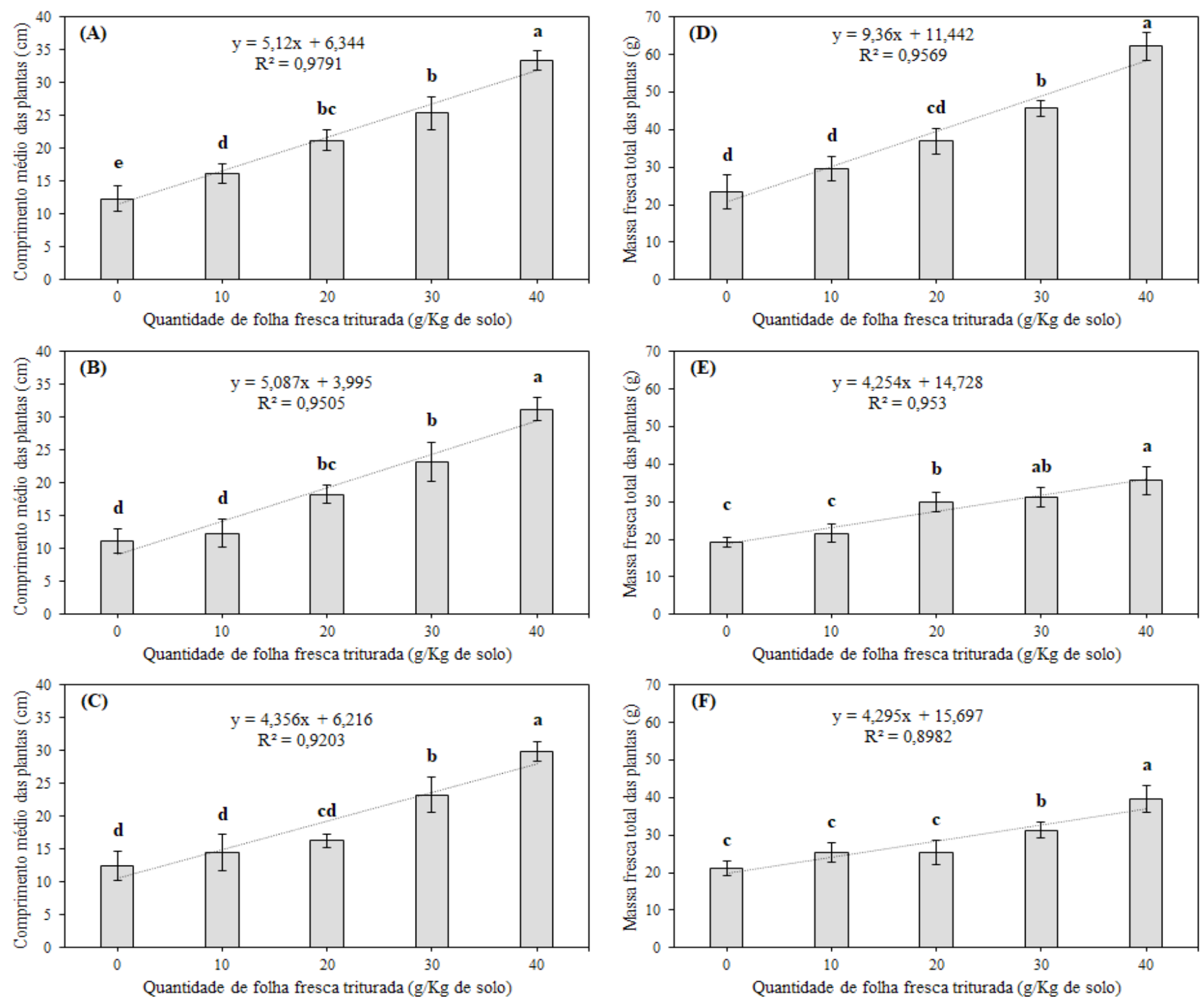

Figura 3. Comprimento médio $(\mathrm{cm})(\mathrm{A}, \mathrm{B}$ e C $)$ e massa fresca total $(\mathrm{g})(\mathrm{D}, \mathrm{E}$ e $\mathrm{F})$ de tomateiros cultivados na presença de resíduos vegetais de folhas de leucena (A e D), mamona (B e E) e mandioca (C e F), 45 dias após deposição dos resíduos sobre o substrato de cultivo das plantas. Letras minúsculas, dentro de um mesmo gráfico, não diferem entre si pelo teste de Tukey $(\mathrm{p}=0,05)$. As barras sobre as colunas representam o erro padrão da média. 
nesses parâmetros foram observados em plantas que receberam folhas de leucena, planta leguminosa e, por isso, com alta concentração de nitrogênio biodisponível, macro elemento responsável pelo melhor desenvolvimento de plantas (Figuras 3A e 3D).

A partir dos resultados apresentados foi possível verificar que o efeito dos materiais vegetais aplicados na forma de cobertura do solo no cultivo do tomate, deu-se tanto na redução da incidência e severidade das galhas produzidas por $M$. Incognita, como também, na melhoria do desenvolvimento das plantas, refletida no aumento da massa fresca total da planta. Além disso, em ambientes sem o patógeno, esses efeitos promotores de crescimento, foram ainda mais pronunciados.

Folhas frescas de leucena, mamona e mandioca, aplicados em cobertura no no solo de cultivo de tomate, produzidos em condição de casa-de-vegetação, reduzem a incidência e severidade do nematoide das galhas, $M$. incognita nas plantas. Noas condições em que os ensaios descritos foram conduzidos, quanto maior o volume de resíduos aplicados, maiores são os efeitos observados. Além disso, em sistemas de cultivo livres do patógeno, os materiais vegetais incrementam o desenvolvimento das plantas, podendo, portanto, ser utilizados como adubos verdes, especialmente, a leguminosa Leucaena leucocephala.

\section{AGRADECIMENTOS}

À Fundação de Amparo à Pesquisa e ao Desenvolvimento Científico e Tecnológico do Maranhão - FAPEMA, pelo suporte financeiro a esta pesquisa.

\section{REFERÊNCIAS}

1. Adekunle, O.K.; Akinlua, A. Nematicidal effects of Leucaena leucocephala and Gliricidia sepium extracts on Meloidogyne incognita infecting okra. Journal of Agricultural Science, Toronto, v.52, n.1, p.53-63, 2007.

2. Agbenin, N.O.; Emechebe, A.M.; Marley, P.S. Evaluation of neem seed powder for Fusarium wilt and Meloidogyne control on tomato. Archives of Phytopathology and Plant Protection, Cambridge, v.37, n.4, p.319326, 2004.

3. Alves, E.C.; Santiago, A.D.; Eloy, A.P.; Amorim, E.P.R. Efeito tóxico da manipueira sobre Scutellonema bradys, causador da "casca-preta" no inhame (Dioscorea cayennensis). Fitopatologia Brasileira, Brasília, DF, v.31, p.74, 2006. Suplemento.

4. Charcar, J.M.; Vieira, J.V.; Oliveira, V.R.; Moita, A.W. Cultivo e incorporação de leguminosas, gramíneas e outras plantas no controle de Meloidogyne incognita raça 1 em cenoura 'Nantes'. Nematologia Brasileira, Botucatu, v.33, n.2, p.139-146, 2009

5. Cunha, F.R.; Oliveira, D.F.; Campos, V.P. Extratos vegetais com propriedades nematicidas e purificação do princípio ativo do extrato de Leucaena leucocephala. Fitopatologia Brasileira, Botucatu, v.28, n.4, p.438-441, 2003.

6. Dias-Arieira, C.R.; Ferraz, S.; Freitas, L.G.; Mizobutsi, E.H. Avaliação de gramíneas forrageiras para o controle de Meloidogyne incognita e $M$. javanica (Nematoda). Acta Scientiarum. Agronomy, Maringá, v.25, n.2, p.473-477, 2008.

7. Dinardo-Miranda, L.L.; Fracasso, J.V. Efeito da torta de mamona sobre populações de nematoides fitoparasitos e a produtividade da cana-de-açúcar. Nematologia Brasileira, Botucatu, v.34, n.1, p.68-71, 2010.

8. Dufour, R.; Earles, R.; Martin, G. Alternative nematode control. Feyettet ville: NCAT, 2003. 16p. Disponível em: < http://www.oisat.org/downloads/ nematode.pdf $>$. Acesso em: 20 ago. 2017.

9. Dutra, M.R.; Paiva, B.R.T.L.; Mendonça, P.L.P.; Gonzaga, A.; Campos, V.P.; Castro Neto, P.; Fraga, A.C. Utilização de silicato de cálcio e torta de mamona no controle do nematoide Meloidogyne exigua em cafeeiro irrigado. In: Congresso Brasileiro de Mamona, 2., 2006, Aracaju. Anais. Aracaju: CBM, 2006. 1 CD-ROM.

10. Ferraz, S.; Freitas, L.G.; Lopes, E.A.; Dias-Arieira, C.R. Manejo sustentável de fitonematoides. 1.ed. Viçosa, MG: Editora UFV, 2010. 306p.

11. Gonzáles, A.; Canto-Sáenz, M. Comparación de cinco enmiendas orgânicas em El control de Globodera pallida em microparcelas em Peru. Nematrópica, Paleon Springs, v.23, n.2, p.133-139, 1993.

12. Grabowski, M.M.S.; Davi, J.J.S.; Nasu, E.G.C.; Layter, N.A.; Seifert, K.E.; Fulanetto, C. Efeito da manipueira, produzida na região Oeste do Paraná, no controle de Tubixaba tuxaua. Fitopatologia Brasileira, Botucatu, v.31, p.74, 2006. Suplemento.

13. Herrera, S.; Marbán-Mendoza, N. Efecto de coberturas vivas de leguminosas en el control de algunos fitonematodos del café em Nicaragua. Nematrópica, Paleon Springs, v.29, n.2, p.223-232, 1999.

14. Hussey, R.S.; Barker, K.R. A comparison of methods of collecting inocula of Meloidogyne spp. including a new technique. Plant Disease Reporter, Palo Alto, v.57, n.3, p.1025-1028, 1973.

15. Ihedó, M.J. Consumidores tornaram-se parceiros da agricultura familiar. Brasília, DF: Secretaria Especial de Agricultura Familiar e Desenvolvimento Agrário, 2017. Disponível em: <http://www.mda.gov.br/sitemda/noticias/ consumidores-tornam-se-parceiros-da-agricultura-familiar $>$. Acesso em: 02 set. 2017.

16. Lima-Medina, I.; Gomes, C.B.; Rossi, C.; Carneiro, R.M.D.G. Caracterização e identificação de populações de nematoide das galhas provenientes de figueiras (Ficus carica L.) do Rio Grande do Sul de São Paulo. Nematologia Brasileira, Botucatu, v.30, n.2, p.179-187, 2006.

17. Lupwayi, N.Z.; Haque, I. Mineralization of NPK, Ca and Mg from Sesbonia and Leucaena leaves varying in chemical composition. Soil Biology and Biochemistry, Sitges, v.30, p.337-343, 1998.

18. Melo, A.; Cunha, S.C.; Mansilha, C.; Aguiar, A.; Pinho, O.; Ferreira, I.M. Monitoring pesticide residues in greenhouse tomato by combining acetonitrile-based extraction with dispersive liquid-liquid microextraction followed by gas-chromatography-mass spectrometry. Food Chemistry, Norwich, v.135, n.3, p.1071-1077, 2012.

19. Nasu, E.G.C.; Pires, E.; Fermentini, H.N.; Furlanetto, C. Efeito de manim pueira sobre Meloidogyne incognita em ensaios in vitro e em tomateiros em casa de vegetação. Tropical Plant Pathology, Brasília, DF, v. 35, n.1, p.32-36, 2010.

20. Quist, C.W.; Smant, G.; Helder, J. Evolution of plant parasitism in the phylum Nematode. Annual Review of Phytopathology, Palo Alto, v.53, n.1, p.289-310, 2015.

21. Rodriguez-Kabana, R.; Canullo, G.H. Cropping systems for the management of phytonematodes. Phytoparasitica, Bet Dagan, v.20, n.3, p.211-224, 1992.

22. SAGRIMA. Balanço 2016 SAGRIMA. [S.1.: s.n.], 2016. Disponível em $<$ http://www.sagrima.ma.gov.br/files/2017/05/balan\%C3\%A7o-2016.pdf $>$ Acesso em: 07 set. 2017.

23. Shirahige, F.H.; Melo, A.M.; Puqueiro, L.F.V.; Carvalho, C.R.L.; Melo, P.C.T. Produtividade e qualidade de tomates Santa Cruz e Italiano em função do raleio de frutos. Horticultura Brasileira, Vitória da Conquista, v.28, n.3, p.292-298, 2010.

24. Silva, M.S.; Bandeira, M.A.; Maranhão, S.R.V.L.; Carvalho, R.M.; Pedroasa, E. M. R. Comportamento de genótipos RB de cana-de-açúcar ao parasitismo dos nematoides das galhas. Revista Brasileira de Ciências Agrárias, Recife, v.11, n.2, p.73-79, 2016.

25. Souza, A.R.L.; Machado, J.A.D.; Dalcin, D. Análise de estudos internacionais sobre os fatores que influenciam a decisão dos agricultores pela produção orgânica. Revista em Agronegócio e Meio Ambiente, Maringá, v.8, n.3, p.563, 2015.

26. Souza, R.N. Potencial do óleo essencial de Lippia alba (Mill) N. E. Brown. no controle de Meloidogyne javanica em plantas de alface. 2017. 35f Monografia (Graduação em Tecnologia em Agroecologia)-Universidade Federal do Recôncavo da Bahia, Cruz das Almas, Bahia.

27. Taylor, A.L.; Sasser, J.N. Biology, identification and control of root-knot nematodes (Meloidogyne spp.). 7th.ed. North Carolina: North Caroline State University Graphics, 1978. 111p.

28. Willer, H.; Yussefi, M. The world of organic agriculture 2005: statistics and emerging trends. 7th.ed. Bonn: IFOAM Publication, 2005. 197p. 